\title{
NILAI-NILAI PENDIDIKAN BUDI PEKERTI LUHUR DALAM CERITA RAKYAT DAERAH LAMONGAN
}

\author{
Hendrik Furqon \\ Ernaningsih \\ Universitas Islam Darul `Ulum Lamongan \\ Email : hendrikfurqon@unisda.ac.id
}

\begin{abstract}
Abstrak: Tujuan dari penelitian ini di fokuskan penemuan (1) nilai-nilai pendidikan budi pekerti luhur yang terkandung dalam cerita rakyat Lamongan (2) Struktur naratif teks Cerita Rakyat Lamongan. Adapun metode yang digunakan dalam penelitian ini adalah kualitatif deskriptif dengan pendekatan nilai Pendidikan dalam karya sastra (pragmatic). Data dalam penelitian ini berupa data tentang (1) Nilai-nilai pendidikan budi pekerti luhur yang terkandung dalam cerita rakyat Lamongan dan (2) Struktur naratif teks Cerita Rakyat Lamongan. Sumber data diperoleh dari dokumentasi dan wawancara. Adapun teknik pengumpulan data dilakukan dengan dokumentasi dan wawancara. Teknik analisis data menggunakan teknik interaktif. Validasi data menggunakan triangulasi, baik triangulasi teori, data, dan metode. Hasil temuan penelitian dapat dideskripsikan meliputi: (1) nilai pendidikan budi pekerti luhur yang terkandung dalam cerita rakyat Lamongan meliputi nilai-nilai mitra, nilai-nilai tresna, nilai-nilai Gembira, dan, nilai-nilai Upeksa. , (2). Struktur naratif teks Cerita Rakyat Lamongan.
\end{abstract}

Kata kunci : nilai, pendidikan, budi pekerti luhur, cerita rakyat

\begin{abstract}
The purpose of this research is to focus on the discovery (1) the educational values of noble character contained in Lamongan folklore (2) the narrative structure of the text of the Rakyat Lamongan story. The method used in this research is qualitative descriptive with an educational value approach in literary works (pragmatic). The data in this study are data about (1) the values of noble character education contained in Lamongan folklore and (2) the narrative structure of the text of the Rakyat Lamongan story. Data sources are obtained from documentation and interviews. The data collection techniques are carried out with documentation and interviews. Data analysis techniques use interactive techniques. Data validation uses triangulation, both triangulation of theories, data, and methods. The findings of the research can be described include: (1) the value of noble character education contained in Lamongan folklore includes the values of partners, traditional values, happy values, and, upeksa values. , (2). Narrative structure of the text of Rakyat Rakyat Lamongan.
\end{abstract}

Keywords: value, education, noble characteristic, folk story

\section{PENDAHULUAN}

Cerita Rakyat merupakan bentuk

karya sastra yang dilatarbelaknagi oleh kehidupan social masyarakatnya. Fenomena sosial dalam karya sastra adalah kenyataan sosial yang mengalami proses pengolahan pengarangnya. Karya sastra bukan hanya sekadar kenyataan kehidupan sosial yang ada di masyarakatnya meskipun karya sastra selalu berdasarkan pada kenyataan sosial. Kenyataan sosial yang ditangkap pengarang ini kemudian diberi visi dan diubah sesuai dengan imajinasi sehingga dunia yang tertulis dalam 
karya sastra bukanlah dunia kenyataan yang sesungguhnya (Wardani, 2009:2). ini menunjukkan bahwa realitas pengungkapan dalam karya sastra melalui medium bahasa yang figuratif konotatif memiliki kemampuan yang jauh lebih luas dalam mengungkap masalah- masalah yang ada dalam masyarakat. Karya sastra bukan sematamata fiksi. Sesuai dengan hakikatnya, fiksi diperoleh melalui pemahaman total mengenai fakta (Ratna, 2011:23). Hal ini memberikan bukti bahwa karya sastra bukan sebatas angan-angan atau ekspresi semata. Karya sastra memang fiktif, tetapi bernilai. Susunan kreatif dari sastrawan menjadikan nilai-nilai kehidupan itu tidak terkesan menggurui, akan tetapi disampaikan sebagai pengalaman. Sastra menyajikan berbagai peristiwa untuk diambil manfaatnya oleh pembaca. Sastra juga berusaha untuk menyampaikan ajaran yang bijak bagi pembaca. Pada pemahaman ini, "nilai di dalam karya sastra" dapat sebagai konsep yang jelas bahwa karya sastra adalah karya imajinatif yang di dalamnya memiliki kebenaran dan nilai-nilai kehidupan (Eagleton, 2010:25).

Berkaitan dengan upaya memahami dan mengungkap hubungan antara pesan dengan fakta dan realitas sosial, serta nilai-nilai yang terkandung dalam sebuah teks karya sastra berupa cerita rakyat, dalam penelitian ini dipilih karya sastra berupa cerita rakyat yang berkembang di daerah Lamongan sebagai objek penelitian dengan menggunakan pendekatan pragmatic untuk mengungkap nilai-nilai pendidikan. Pendekatan ini diharapkan dapat mengungkap nilainilai pendidikan budi pekerti luhur yang terdapat dalam teks sastra cerita rakyat Lamongan. Penelitian ini juga diharapkan dapat mengungkap kebermanfaatan karya sastra yang merupakan cerita rakyat dan dapat dipertanggungjawabkan secara ilmiah.

Oleh karena itu, tugas dalam penelitian sastra tidak sekadar harus menafsirkan apa saja yang dipandang aneh dalam karya, melainkan harus memberikan penilaiaan pertanggungjawaban. Penelitian sebaiknya mampu memberikan evaluasi terhadap apa yang diungkap dari karya sastra.

\section{TEORI DAN PEMBAHASAN}

Cerita rakyat merupakan cerita

yang berkembang dan berasal dari masyarakat tertentu. Cerita rakyat dalam perkembangannya mengalami fase secara turun temurun dan penyampaiannya menggunakan media lisan, sehingga cerita rakyat sering juga disebut dengan cerita sastra lisan. Pada umumnya cerita rakya bersifat anonym atau pengarang cerita tidak dapat ditelusuri atau dikenal dan mempunyai ciri-ciri sebagai berikut; Fase perkembengan turun-temurun, anonym dan tidak diketahui siapa yang pertama kali membuatnya, bersifat tradisi, variatif, bersifat klise, berkembang dari mulut kemulut (lisan).,Cerita rakyat atau sastra lisan adalah kesastraan yang mencangkup ekspresi kesastraan warga suatu kebudayaan yang disebarkan dan turun temurun secara lisan, (Hutomo, 1991:1).

Cerita rakyat dibagi menjadi dua bagian yaitu sastra lisan primer dan sastra lisan sekunder. Perpedaan dari keduanya terletak pada ciri masingmasing yaitu: Ciri-ciri sastra lisan primer : Penyebarannya melalui mulut ke mulut yang disebarkan baik dari segi waktu maupun ruang melalui percakapan. Lahir didalam masyarakat yang masih bercorak desa, masyarakat diluar kota atau masyralat yang belum mengenal huruf. Menggambarkan ciri 
budaya suatu masyarakat, Tidka diketahui siapa pengarangnya dan karena itu menjadi milik masyarakat, Bercorak puitis teratur dan berulangulang, Tidak menenekankan fakta dan kebenaran, lebih menekankan pada aspek khayalan atau fantasi yang tidak diterima oleh masyarakat modern, tetapi sastra lisan meliki fungsi penting didalam masyarakat. Terdiri atas berbagai versi Bahasa menggunakan gaya bahasa lisan (sehari-hari) mengandung dialek, terkadang tidak lengkap (Hutomo,

1991:3-4). Sedangkan sastra lisan sekunder merupakan sistem produksi sastra tulis, sebagai perwujudan, penyebar luasan informasi atau sosialisa sastra tulis. Jika dilihat dari segi penuturnya sastra lisan dibagi menjadi dua, yaitu: Sastra lisan yang bernilai sastra (mengandung estetika), Sastra lisan yang tidak bernilai sastra.

Nilai-nilai yang menjadi milik bersama di dalam satu masyarakat menjadi perekat bagi masyarat itu. Kalau suatu masyarakat telah mempunyai nilai yang sama tentang yang berguna dan tidak berguna, tentang yang cantik dan tidak cantik, tentang yang baik dan buruk, maka masyarakat yang seperti itu seolah-olah telah direkat oleh suatu norma yang sama, sehingga anggota masyarakat itu akan mempunyai rasa solidaritas yang tinggi. Jadi kalau nilai- nilai ini telah menjadi milik bersama dan telah tertanam dengan emosi yang mendalam, maka anggota masyarakat itu akan bersedia berkorban dan berjuang untuk mempertahankan nilainilai itu. Hal tersebut menunjukkan bahwa nilai merupakan fenomena psikis manusia yang menganggap bahwa sesuatu hal bermanfaat dan berguna bagi kehidupannya (Waluyo,2003:78). Adapun pengertian pendidikan dapat dirunut dalam beberapa konteks. Semisal, dari segi bahasa, pendidikan dapat diartikan perbuatan (hal, cara dan sebagainya) mendidik; dan berarti pula pengetahuan tentang mendidik, atau pemeliharaan (latihan-latihan dan sebagainya) badan, batin dan sebagainya (Poerwadarminta, 1991). Menurut M.J. Langeveld (dalam Elmubarok, 2009:2) pendidikan adalah memberi pertolongan secara sadar dan sengaja kepada seoarang anak (yang belum dewasa) dalam pertumbuhannya menuju ke arah kedewasaan, dalam arti dapat berdiri dan bertanggung jawab susila.

Budi pekerti luhur budaya Jawa sebenarnya berpangkal pada penghayatan perbuatan buruk manusia pada keserakahan dan keirihatian manusia. Selama manusia belum bisa sampai mengendalikan dua nafsu tersebut manusia akan selalu mengadapi segala persoalan dengan urusan keduniaannya. Sifat-sifat ini akan mendorong manusia untuk selalu berbuat buruk pada sesamanya dan merugikan orang lain dan dirinya sendiri. Berusaha untuk berbuat baik dan meninggalkan dua sifat buruk tadi memang sukar untuk dilakukan. Namun untuk menuju sikap berbudi pekerti luhur manusia harus mampu mewujudkan berbuat baik kepada orang lain tanpa pamrih. Berbuat baik memang semata-mata dilakukan untuk kebaikan dan tidak ingin dipuji atau ada imbalan tersendiri, pamrih (Marbangun,1983:63-64).

Sikap berbudi luhur pada masyarakat Jawa biasanya diajarkan lewat guru spiraitual, tokoh-tokoh keagamaan, guru dan para pujangga. Seperti halnya tergambar dalam kebudayaan Jawa, bagaimana seseorang bisa mempelajari ajaranajaran budaya Jawa dengan baik, budi pekerti manusia Jawa yang luhur. 
Ajaran budi pekerti dan budi luhur budaya Jawa, berkiblat pada ajaran yang ada pada kebudayaan keraton Surakarta dan Yogyakarta.

Dalam penelitian ini sikap budi pekerti luhur budaya menganut visi empat perbuatan luhur untuk mencapai kehidupan sempurna, Mitra, Tresna, Gembira dan Upeksa. Hal ini diambil dari buku etika Jawa menggali kebijaksanaan dan keutamaan demi ketentraman Hidup Lahir Batin (Widyawati :64).

\section{Mitra}

Mitra yang dimaksud di sini adalah kawan, sahabat, saudara, atau teman. Berarti sifat yang menghendaki persahabatan terhadap semua makluk. Mengajarkan agar manusia memandang semua manusi seperti keluarga besar. Manusia wajib mengasihi, tolong menolong dan menghormati. Seperti tergambar dalam cerita Lamongan berikut: LARAS-LIRIS. Dan ANDANWANGI ANDAN SARI. Tresna berarti saling cinta kasih, yaitu perasaan belas kasihan kepada semua makluk yang menderita. Sifat suka menolong dan rela berkorban demi kebahagian orang lain. Selalu merasakan penderitaan orang lain, suka mengampuni dan memaafkan orang lain. Seperti tergambar dalam cerita Lamongan berikut:

DESA TELANAK. Gembira adalah sikap bahagia, puas dan simpati yang tidak pernah dikotori oleh sifat iri hati, dengki dan benci. Orang diharapkan memiliki sifat sedih bila melihat orang mengalami penderitaan dan mereka berusaha untuk membantunya. Demikian pula sebaliknya merasa bahagia dengan melihat kebahagian orang lain. Seperti tergambar dalam cerita Lamongan berikut: MBOK RONDO GONDANG. Upeksa adalah sifat yang tidak
Humanis Vol 11 No 2

mencampuri urusan orang lain. Upeksa mengajarkan kepada manusis untuk selalu waspada dan bijkasana dalam meneliti segala tindakan, keadaan atau suatu masalah, apakah suatu masalah itu benar atau salah. Sifat upeksa tidak suka menceritakan kesalahan dan kejelekan orang lain, tidak suka menyinggung perasaan orang lain. Seperti tergambar dalam cerita Lamongan berikut: RONDO KUNING.

\section{SIMPULAN}

Berdasarkan temuan dari penelitian ini dapat disimpulkan bahwa hasil penelitian terhadap cerita rakaya lamongan diklasifikasika ke dalam1. Struktur naratif Cerita Rakyat Lamongan, Nilai Pendidikan Budi Pekerti luhur dalam cerita rakyat di lamongan!, Menemukan Pemaham nilai-nilai pendidikan budi pekrti luhur diantaranya karakter dalam Kejujuran, nilai-nilai mitra, nilainilai tresna, nilai-nilai Gembira, dan, nilai-nilai Upeksa.

Nilai-nilai tersebut muncul dikarenakan tema-tema cerita rakyat Lamongan syarat memberikan edukasi kepada pembacanya untuk melakukan sesuai nila-nilai yang ada di masyarakat.

\section{DAFTAR PUSTAKA}

Abrams, M.H. 1981. The Mirror and The Lamp. Oxford: Oxford University Press.

Bratawijaya, Thomas Wiyasa. 1997. Mengungkap dan Mengenal Budaya Jawa. Jakarta: PT Pradanya Paramita.

Danandjaja, James. 1991. Folklor Indonesia Ilmu Gosip Dongeng dan lain-lain. Jakarta: Pustaka Grafiti.

Eagleton, Terry. 2010. Teori Sastra: Sebuah Pengantar Kompehensif. Yogyakarta: Jalasutra. 
Edraswara, Suwandi. DKK. 1966. Nilai Budaya Dalam Beberapa Karya Sastra Nusantara:

Edraswara, Suwandi. 1986. Metode Penelitian Sastra Lisan. Jakarta: PT Buku Kita.

Hutomo, Suripan Sadi. 1991. Mutiara Yang Terlupakan. Surabaya: Hiski. Levi-Strauss, Claude. 2005. Antropologi Struktural. Yogyakarta: Kreasi Wacana

Mulder, Niel. 2007. Mistisisme Jawa: Ideologi di Indonesia. Yogyakarta: LKIS

PBSI Unisda. 2017 . Antologi Cerita Rakaya (Jejak Yang Tertinggal), : Lamongan: Pustaka Ilalang.

PBSI Unisda, 2016 . Fiksi Naratif (Foklor Masyarakat Lamongan, Gresik, dan Bojonegoro), Lamongan: Pustaka Ilalang

Wardani, Nugraheni Eko. 2009. Makna Totalitas dalam Karya Sastra. Surakarta: UNS Press.

Widyawati, Wiwin.2010. Etika Jawa.Pura Pustaka: Yogyakarta Yuwana Sudikan, Setya. 2001. Metode Penelitian Sastra Lisan. Surabaya: Citra Wacana. 